\title{
VGEFR/c-kit/PDGFR Tyrosine Kinase Inhibitor XL820
}

National Cancer Institute

\section{Source}

National Cancer Institute. VGEFR/C-kit/PDGFR Tyrosine Kinase Inhibitor XL820. NCI

Thesaurus. Code C49090.

An orally bioavailable, small molecule receptor tyrosine kinase inhibitor with potential antineoplastic activity. XL820 binds to and inhibits the receptor tyrosine kinases for vascular endothelial growth factor (VEGF), c-kit, and platelet-derived growth factor (PDGF). In tumor models of breast carcinomas, gliomas, and leukemia, this agent exhibits dose-dependent growth inhibition and has been shown to cause tumor regression. 